\title{
Eye banking and corneal transplantation in Tertiary care hospital located in rural area
}

\author{
Sonu Lohiya ${ }^{1}$, Ruchita Attal $^{2}$, Pradeep Bokariya ${ }^{3}$ \\ ${ }^{1}$ Associate Professor, Ophthalmology Mahatma Gandhi Institute of Medical Sciences \\ ${ }^{2}$ Assistant Professor, Microbiology, Mahatma Gandhi Institute of Medical Sciences \\ ${ }^{3}$ Assistant Professor, Anatomy, Mahatma Gandhi Institute of Medical Sciences
}

\begin{abstract}
Considering the magnitude of corneal blindness and shortage of donor material, more marked in rural area this study about eye banking and corneal transplantation was conducted in tertiary care hospital located in rural area. This study was conducted in the Department of Ophthalmology, Kasturba Hospital, Mahatma Gandhi Institute of Medical Sciences, Sevagram from January 2008 to December 2012.It is a hospital based prospective study.
\end{abstract}

\section{Keywords - Eye Banking, Corneal Transplant}

\section{INTRODUCTION}

As a highly specialized tissue, the cornea is avascular, refractive and almost unique in its transparency There are an estimated 4.9 million bilaterally corneal blind persons worldwide who could potentially have their sight restored through corneal transplantation[1]. Unilateral corneal blindness is not captured in WHO data, but is estimated to occur in 23 million globally, based on India's bilateral-unilateral ratios of $0.1 \%$ to $0.56 \%$ prevalence.[2] More startling is the rate of new unilateral corneal blindness cases, with one prospective study in Nepal indicating an annual incidence of corneal ulceration to be 799 per 100,000 people, primarily unilateral ulcerations.[3] In a southern India-based study, corneal blindness has been projected to grow from $0.66 \%$ (2001) to $0.84 \%$ (2020) prevalence, largely from unilateral cases.

Eye donation is again very less in rural area because of illiteracy, poverty, superstitions and lack of knowledge and communication in rural area. In 1906, Zirm achieved the first successful penetrating corneal graft in human.

Considering the magnitude of corneal blindness and shortage of donor material, more marked in rural area this study about eye banking and corneal transplantation was conducted in tertiary care hospital located in rural area.

\section{MATERIAL AND METHOD}

This study on was conducted in the Department of Ophthalmology, Kasturba Hospital, Mahatma Gandhi Institute of Medical Sciences, Sevagram from January 2008 to December 2012.It is a hospital based prospective study All new conseutive patient attending the out patients department of ophthalmology were screened for corneal disorders and visual status. After complete ocular examination and required investigations Patients suffering from corneal blindness were registered in cornea clinic.80 patients operated for PK at our institute between January 2008 to December 2012 and those who completed at least one year follow up were included for analysis and were reviewed for demographic data, indications for keratoplasty, surgical techniques, postoperative best-corrected visual acuity (BCVA), postoperative refraction, graft clarity, and complications. The effect of age, socioeconomic status and sex on the distribution of these indications was studied. In all cases, interrupted suturing with 10/0 nylon was done. Routine follow-up schedule was every weekly for first month, biweekly for second month, monthly for 3 to 6 months, and every three months for one year. Patients compliant with this schedule were called "Regular Follow Ups." Selective suture removal was started from third month onward, after assessing tightness of sutures on slit lamp examination, and calculating astigmatism by Retinoscopy. 


\section{PROFILE OF DONORS}

\section{OBSERVATIONS}

Out of 120 eye balls collected $48(40 \%)$ were from persons aged more than 70 years Mean age of donors was $64.4 \pm 13.2$ years .Large distance of donor house from Eye Bank increased the travel time which increased the time interval between the collection of eye ball and processing of eye ball in the Eye Bank before it could be used or preserved. In majority $(53.3 \%)$ of the cases the time interval between death of the donor and enucleation was 4-6 hours (Table 3,).Donor rim culture was noted to be sterile in 104 (86.6\%) corneo -scleral buttons. Culture from donor rim revealed presence of microorganism in 16 (13.4\%) eye balls . Coagulase negative staph was noted in $8(6.7 \%)$, coagulase positive staph in $4(3.3 \%)$, Gram negative bacilli in $2(1.7 \%)$ and Mixed growth was noted in $2(1.7 \%)$ donor rim culture

\section{QUALITY OF DONOR CORNEA}

On corneal tissue evaluation out of 120 eye balls collected 34 (28.3\%) were found not suitable for corneal transplantation. Corneal tissue was graded as Good in $44(36.7 \%)$ eyes and Fair in $22(18.3 \%)$ eyes. Donor tissue was graded Excellent / Very Good in only 20 (16.7\%) eyes. Out of 120 eyeballs collected during study period $34(28.3 \%)$ were found to be not suitable for corneal transplantation surgery and $6(5.0 \%)$ had poor endothelial cell density (less than 1500 cells $/ \mathrm{mm}^{2}$ ) on specular microscopy.

\section{INDICATIONS FOR CORNEAL TRANSPLANTATION}

Out of 80 patients included in this study who underwent corneal transplantation 58 (72.5\%) had Penetrating Keratoplasty performed for Optical purpose and remaining 22(27.5\%) underwent Penetrating Keratoplasty for therapeutic reasons. Corneal transplantation were performed for varied disorders. Out of 58 patients for whom optical penetrating keratoplasty was done, majority of them $36(62.1 \%)$ had corneal scar. (Table 1)

Out of 22 patients who had undergone therapeutic penetrating keratoplasty $14(63.6 \%)$ patients had severe bacterial / fungal keratitis, $6(27.3 \%)$ patients had perforated corneal ulcer and 2( $9.1 \%)$ patients had sloughing corneal ulcer. (Table 2)

\section{DEMOGRAPHIC PROFILE OF RECIPIENTS}

Out of 80 patients included in this study who underwent corneal transplantation 60(75.0\%) were males $20(25.0 \%)$ were females. Mean age of patients was $47.6 \pm 18.8$ years ranging from 11 years to 75 years.

Mean age of female patients was $43.1 \pm 20.6$ years ranging from 18 years to 70 years whereas mean age of male patients was $49.1 \pm 18.3$ years ranging from 11 years to 75 years. Majority of patients in this study $38(47.5 \%)$ were aged above 50 years, $20(25.0 \%)$ were aged $11-30$ years and $22(27.5 \%)$ were aged 31-50 years. (Table 3 )

\section{SOCIO ECONOMIC STATUS OF RECIPIENTS}

Out of 80 patients, $52(65.0 \%)$ were socio-economically from below poverty line status while 18 (22.5\%) were of low income group and $10(12.5 \%)$ were of middle class. Majority of patients $52(65.0 \%)$ were illiterate , $18(22.5 \%)$ patients were educated only till primary class and only $10(12.5 \%)$ were educated till secondary school or beyond.

In addition to penetrating keratoplasty Lens surgery was done in 44 (55.0\%) eyes, Glaucoma surgery in $42(52.5 \%)$ eyes, Anterior vitrectomy in 18 (22.5\%) eyes and Lid / Sac surgery in 8(10.0\%) eyes each. (Table 4)

\section{OUTCOME OF CORNEAL TRANSPLANTATION}

\section{POST-OPERATIVE VISUAL STATUS}

Out of 80 eyes included in this study in whom penetrating keratoplasty was performed post operative visual acuity in the operated eye was found to be >6/60 in $20(25.0 \%)$ eyes and $20(25.0 \%)$ eyes had visual acuity $<6 / 60-3 / 60$. In $26(32.5 \%)$ eyes post operative visual acuity was $<3 / 60-1 / 60$ and $14(17.5 \%)$ eyes had post operative visual acuity $<1 / 60$ to Perception of light. (Table 5)

\section{ASTIGMATISM}

Out of 80 eyes included in this study in whom penetrating keratoplasty was performed post operative corneal astigmatism on keratometry was recorded 8-12 weeks after corneal transplantation. Keratometry could 
be satisfactorily performed only in $42(55.0 \%)$ eyes. Keratometry could not be performed in 28 (35.0\%) eyes and irregular mires were noted in $10(12.5 \%)$ eyes.

Astigmatism less than $3 \mathrm{D}$ was noted in $20(25.0 \%)$ eyes, $14(17.5 \%)$ had astigmatism between $3 \mathrm{D}-6$ $\mathrm{D}$ and astigmatism more than $6 \mathrm{D}$ was noted in $8(10.0 \%)$ eyes. (Table 6$)$

\section{POST OPERATIVE COMPLICATIONS}

Out of 80 eyes included in this study in whom penetrating keratoplasty was performed post operative complications were noted in $36(45 \%)$ eyes. Graft failure w as noted in 26(32.5\%) eyes, Persistent epithelial defect in $4(5.0 \%)$ eyes and wound leak, suture infiltration, recurrence of fungal keratitis was noted in $2(2.5 \%)$ eye each. (Table 7)

\section{DISCUSSION}

This hospital based prospective study on "Eye Banking and Corneal Transplantation in Tertiary Care Hospital Located in Rural Area " was conducted in the Department of Ophthalmology, Kasturba Hospital, Mahatma Gandhi Institute of Medical Sciences, Sevagram from January 2008 to december 2012.

\section{DONOR PROFILE}

In the present study majority of the donors $92(76.7 \%)$ were aged more than 60 years and only 16 ( $13.3 \%$ ) eye balls collected from donors aged less than 40 years. Mean age of donors was $64.4+13.2$ years. Patel et al. (2005), reported in their prospective longitudinal study that out of 3221 corneas retrieved from 1628 donors the mean age of donors was $59.4+18.3$ years and no significant correlation was identified between donor age group and the proportion of corneas suitable for transplantation. [4]

Meyer et al. (2001), in their prospective study compared eyes that had undergone penetrating keratoplasty and had received either transplants from young donors aged $<55$ years or from donors aged $>55$ years with a presumed bad prognosis and reported that there is no significant difference in graft survival, visual outcome and endothelial cell counts between these groups after 15 years of follow up.

In the present study donor rim culture was noted to be sterile in $104(86.6 \%)$ corneoscleral buttons and revealed presence of microorganism in $16(13.4 \%)$ cases . Coagulase negative staph was noted in 8 ( $6.7 \%)$, coagulase positive staph in 4(3.3\%), Gram negative bacilli in $2(1.7 \%)$ and Mixed growth was noted in $2(1.7 \%)$ donor rim culture.

Patel et al. (2005), reported that biologic contamination occurred in 5\% of all donor corneas. The most common bacterial and fungal isolates were coagulase-negative staphylococci and Candida. Everts et al. (2001) reported that $5.3 \%$ of corneal scleral rim cultures yielded microorganism, mostly coagulase-negative staphylococci but preoperative donor corneoscleral rim cultures are unreliable predictors of endophthalmitis complicating corneal transplantation. [5] Kloess et al (1992) had reported that in 30 out of 31 cases of positive donor rim cultures, the isolated organism was the same genus and species as the organism that caused the endophthalmitis following penetrating keratoplasty.

\section{QUALITY OF DONOR CORNEA}

Out of 120 Eyeballs collected and processed during the study period $80(66.7 \%)$ were found suitable and used for corneal transplantation. Out of these $58(72.5 \%)$ were used for Penetrating Keratoplasty performed for Optical purpose and remaining 22(27.5\%) were utilized for therapeutic Penetrating Keratoplasty.

Patel et al (2005) reported the utilization and distribution of corneal tissue procured by New Zealand National Eye Bank that out of 3221 corneas retrieved from 1628 donors only $79.4 \%$ of corneal tissue procured was used for corneal transplantation (75.8\% for penetrating keratoplasty, $2.1 \%$ for lamellar keratoplasty, and $1.5 \%$ for unspecified transplants), and $21.6 \%$ was discarded. Most common reasons for discarding tissue were biologic contamination, abnormal serology, and failed endothelial assessment.

\section{INDICATIONS OF CORNEAL TRANSPLANTATION}

In the present study out of 58 patients for whom optical penetrating keratoplasty was done, majority of them $36(62.1 \%)$ had corneal scar. Out of 22 patients who had undergone therapeutic penetrating keratoplasty $14(63.6 \%)$ patients had severe bacterial / fungal keratitis

Dandona et al (1997), reported that the indication of PK in India are corneal scarring in 551(28.1\%) including adherent leucoma in $147(7.5 \%)$ regraft in $336(17.15 \%)$. [6] 
Aya Maeno et al (1999) reported that in Canada leading indication for PKP were regraft, kertoconus, PBK, fuch's dystrophy, viral infection and trauma in that order. Legeais et al (2001) reported that in France most common indication for PK were keratoconus (28.8\%), herpetic infections (10.9\%), graft failures (9.9\%). Yousuf et al. (2003) reported that in U.K. the common indications for penetrating keratoplasty were regrafting $(14.9 \%)$, Keratoconus (15\%), Fuch's endothelial dystorophy (9.3\%), Pseudophakic bullous keratopathy (7.6\%) and viral keratitis (8.9\%). Lindquist et al (1991) reported that in USA Keratoconus was the leading indication for penetrating keratoplasty prior to 1985 thereafter for next five years pseudophakic bullous keratopathy became the leading indication[7]

In India corneal scarring, including adherent leucoma, and active infectious keratitis are relatively more common indications whereas keratoconus, pseudophakic bullous keratopathy and Fuchs' dystrophy are less common indications for PK than reported from the developed world.

\section{OUTCOME OF CORNEAL TRANSPLANTATION}

Visual Recovery

In the present study post operative visual acuity in the operated eye was noted to be $>6 / 60$ in 20 $(25.0 \%)$ eyes and $20(25.0 \%)$ eyes had visual acuity $<6 / 60-3 / 60$. In $26(32.5 \%)$ eyes post operative visual acuity was $<3 / 60-1 / 60$ and $14(17.5 \%)$ eyes had post operative visual acuity $<1 / 60$ to Perception of light

Vanathi et al (2005) reported that of the 53 eyes with repeat penetrating keratoplasty the best corrected visual acuity of the 28 clear grafts ranged from $4 / 60$ to $6 / 9$, only 5 eyes (9.4\%) achieved best corrected visual acuity of $6 / 18$ or better at the end of 1 year after re-grafting. [8]

Valery et al (2001) reported that 44 of the 86 eyes $(51 \%)$ had clear grafts, but only $39.5 \%$ had good visual outcome. Visual acuity also decreased with time. Final visual acuity was 20/20 to 20/40 in 13 of the 86 eyes (15\%), 20/80 to 20/200 in 23 eyes (27\%), and less than 20/200 in 50 eyes (58\%).[9]

Claesson et al (2002) reported that visual acuity improvement in patients, with keratoconus and Fuch's dystrophy was $86 \%$ and $54 \%$ respectively compared with only $31 \%$ of bullous keratopathy and $35 \%$ in the "other diagnosis" group.

\section{Post Operative Complications}

In the present study post operative complications were noted in $36(45 \%)$ eyes. Graft failure was noted in $26(32.5 \%)$ eyes, Persistent epithelial defect in $4(5.0 \%)$ eyes and wound leak, suture infiltration, recurrence of fungal keratitis was noted in $2(2.5 \%)$ eye each.

Meyer et al (1987) studied 166 eyes underwent triple procedure and found that the most frequent complication during the postoperative period were glaucoma (40 patients, 24\%), endothelial graft rejection episodes (two-year cumulative risk, 16\%) and astigmatism[10]

Machado et al (2002) analyzed 91 patients who underwent penetrating corneal transplantation reported that $64.84 \%$ of the patients had epithelial defects on the first postoperative day. [11]

Berville et al (1983) reported in his retrospective study of 152 patients an incidence of $24.7 \%$ rejection reaction in patients with epithelium transplanted compared to $7.2 \%$ in the epithelium-removed group[12]

\section{Astigmatism}

In the present study post operative corneal astigmatism on keratometry was recorded 8-12 weeks after corneal transplantation. Astigmatism less than $3 \mathrm{D}$ was noted in 20(25.0\%) eyes, $14(17.5 \%)$ had astigmatism between $3 \mathrm{D}-6 \mathrm{D}$ and astigmatism more than $6 \mathrm{D}$ was noted in $8(10.0 \%)$ eyes. Irregular mires were noted in $10(12.5 \%)$ eyes.

Carmen et al (2002) reported in his study on 30 eyes (28 patients) who underwent keratoplasty for keratoconus that all the patients had a continuous myopic shift to $-1.02 \pm 2.65$ diopters 2 years postoperatively. This was associated with significant increase in the mean keratometry levels from $+41.72 \pm 2.96$ diopters at 1 month postoperatively to $+43.77 \pm 2.29$ diopters 2 years postoperatively. Soong et al (2000) reported that following tectonic keratoplasty the mean \pm SD change in keratometric astigmatism in the parent penetrating keratoplasty was $1.75 \pm 1.50$ diopters. The astigmatism increased in 10 cases $(60.6 \%)$, decreased in three (20\%), and remained unchanged in two (13.3\%).[1]

Claesson et al (2002) reported that Postoperative astigmatism was higher in the bullous keratopathy group (4.7D). 


\section{REFERENCES}

[1]. Geneva: WHO Press; 2009. World Health Assembly Document A62/7: Action plan for the prevention of avoidable blindness and visual impairment. 2009 - 2013; pp. 7-17.

[2]. Dandona R, Dandona L. Corneal blindness in a southern Indian population: Need for health promotion strategies. Br J Ophthalmol. 2003;87:133-41. [PMCID: PMC1771511] [PubMed: 12543736]

[3]. Witcher J, Srinivasan M, Upadhyay MP. Corneal blindness: A global perspective. Bull World Health Organ. 2001;79:214-21. [PMCID: PMC2566379] [PubMed: 11285665]

[4]. Patel et al. The New Zealand National Eye Bank Study 1991-2003: A Review of the Source and Management of Corneal Tissue.

[5]. Cornea. 24(5):576-582, July 2005.Everts, et al. Corneoscleral Rim Cultures: Lack of Utility and Implications for Clinical Decision-making and Infection Prevention in the Care of Patients Undergoing Corneal Transplantation. Cornea. 20(6):586589, August 2001.

[6]. Dandona et al. Indications for penetrating keratoplasty in India. Indian J Ophthalmol 45:163-168,1997.

[7]. Lindquist et al (1981) Indications for penetrating keratoplasty: Cornea 10:210-16, 1991

[8]. Vanathi et al. Indications and outcome of repeat penetrating keratoplasty in India, BMC, Ophthalmology, 5:26, 2005.

[9]. Valery et al. The Profile of Repeated Corneal Transplantation, Ophthalmology 108:461-469,2001.

[10]. Mayer et al. Assessment Of Success And Complications Of Triple Procedure Surgery, American J Ophthalmology 104:233240, September 1987.

[11]. Machado et al. The Relationship between First Postoperative Day Epithelial Status and Eventual Health of the Ocular Surface in Penetrating Keratoplasty. Cornea. 21(6):574-577, August 2002.

[12]. Berville et al. The Effect Of Donor Cornea Epithelium Removal On The Incidence Of Allograft Rejection Reactions, Ophthalmology 90:1351-1356, 1983.

[13]. Soong et al. Small, Overlapping Tectonic Keratoplasty Involving Graft-Host Junction of Penetraing Keratoplasty, American J Ophthalmol 129:465-467, 2000.

TABLE 1 : INDICATIONS FOR OPTICAL PENETRATING KERATOPLASTY

\begin{tabular}{|l|l|}
\hline Corneal Disorders & No. of patients (n=58) \\
\hline Central Corneal Opacity & $20(34.5 \%)$ \\
\hline Adherent Leucoma & $8(13.7 \%)$ \\
\hline Anterior Staphyloma & $4(6.8 \%)$ \\
\hline Post Traumatic Scar & $4(6.8 \%)$ \\
\hline Interstitial Keratitis (Leprosy) & $2(3.4 \%)$ \\
\hline Corneal Dystrophy & $4(6.8 \%)$ \\
\hline Corneal Degeneration & $2(3.4 \%)$ \\
\hline Keratoconus & $2(3.4 \%)$ \\
\hline Pseudophakic Bullous Keratopathy (PBK) & $6(10.3 \%)$ \\
\hline Aphakic Bullous Keratopathy (ABK) & $4(6.8 \%)$ \\
\hline Graft Failure & $2(3.4 \%)$ \\
\hline
\end{tabular}

TABLE 2 : INDICATIONS FOR THERAPEUTIC PENETRATING KERATOPLASTY

\begin{tabular}{|l|l|}
\hline Corneal Disorders & No. of patients $(\mathbf{n = 2 2})$ \\
\hline Fungal Keratitis & $4(18.2 \%)$ \\
\hline Bacterial Keratitis & $10(45.5 \%)$ \\
\hline Perforation / Descemetocele & $6(27.3 \%)$ \\
\hline Sloughing Corneal Ulcer & $2(9.1 \%)$ \\
\hline
\end{tabular}

TABLE 3 : AGE AND SEX DISTRIBUTION OF RECIPIENTS

\begin{tabular}{|l|l|l|l|}
\hline Age of Patients (in years) & Male No. (\%) & Female No. (\%) & Total No. (\%) \\
\hline $11-20$ & $8(13.3 \%)$ & $4(20.0 \%)$ & $12(15.0 \%)$ \\
\hline $21-30$ & $4(6.7 \%)$ & $4(20.0 \%)$ & $8(10.0 \%)$ \\
\hline $31-40$ & $10(16.7 \%)$ & 0 & $10(12.5 \%)$ \\
\hline $41-50$ & $8(13.3 \%)$ & $4(20.0 \%)$ & $12(15.0 \%)$ \\
\hline $51-60$ & $8(13.3 \%)$ & $2(10.0 \%)$ & $10(12.5 \%)$ \\
\hline $61-70$ & $18(30.0 \%)$ & $6(30.0 \%)$ & $24(30.0 \%)$ \\
\hline$>70$ & $4(6.7 \%)$ & 0 & $4(5.0 \%)$ \\
\hline Total & $60(100 \%)$ & $20(100 \%)$ & $80(100 \%)$ \\
\hline
\end{tabular}


Eye banking and corneal transplantation in Tertiary care hospital located in rural area

TABLE 4: ADDITIONAL SURGICAL PROCEDURES IN EYES UNDERGOING CORNEAL TRANSPLANTATION

\begin{tabular}{|c|c|c|c|}
\hline \multirow{2}{*}{$\begin{array}{l}\text { Surgical Procedures performed in } \\
\text { addition to Penetrating Keratoplasty }\end{array}$} & OPTICAL P.K. & THER. P.K. & TOTAL \\
\hline & $\begin{array}{l}\text { No. of Eyes }(\%) \\
(\mathrm{n}=58)\end{array}$ & 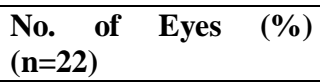 & $\begin{array}{l}\begin{array}{l}\text { No. of } \\
(n=80)\end{array} \\
\left(\begin{array}{l}\text { Eyes } \\
(\%)\end{array}\right.\end{array}$ \\
\hline Lens Surgery & $30(51.7 \%)$ & $14(63.6 \%)$ & $44(55.0 \%)$ \\
\hline Glaucoma Surgery & $32(55.2 \%)$ & $10(45.5 \%)$ & $42(52.5 \%)$ \\
\hline Anterior Vitrectomy & $14(24.1 \%)$ & $4(18.2 \%)$ & $18(22.5 \%)$ \\
\hline Lid Surgery & $2(3.4 \%)$ & $6(27.3 \%)$ & $8(10.0 \%)$ \\
\hline Sac Surgery & 0 & $8(36.4 \%)$ & $8(10.0 \%)$ \\
\hline
\end{tabular}

TABLE 5: POST-OPERATIVE VISUAL STATUS OF EYES WITH PK

\begin{tabular}{|l|l|l|l|}
\hline \multirow{2}{*}{ Best Correct Visual Acuity } & OPTICAL P.K. & THER. P.K. & TOTAL \\
\cline { 2 - 4 } & No. of Eyes $(\%)(\mathbf{n = 5 8})$ & No. of Eyes $(\%)(\mathbf{n = 2 2})$ & No. of Eyes $(\boldsymbol{\%})(\mathbf{n}=\mathbf{8 0})$ \\
\hline$\geq 6 / 18$ & $4(6.8 \%)$ & 0 & $4(5.0 \%)$ \\
\hline$<6 / 18-6 / 60$ & $16(27.5 \%)$ & 0 & $16(20.0 \%)$ \\
\hline$<6 / 60-3 / 60$ & $16(27.5 \%)$ & $4(18.2 \%)$ & $20(25.0 \%)$ \\
\hline$<3 / 60-1 / 60$ & $14(24.1 \%)$ & $12(54.6 \%)$ & $26(32.5 \%)$ \\
\hline$<1 / 60-P L+$ & $8(13.7 \%)$ & $6(27.3 \%)$ & $14(17.5 \%)$ \\
\hline
\end{tabular}

TABLE 6: CORNEAL ASTIGMATISM ON KERATOMETRY IN EYES AFTER P.K.

\begin{tabular}{|l|l|l|l|}
\hline \multirow{2}{*}{$\begin{array}{l}\text { Astigmatism on } \\
\text { Keratometry }\end{array}$} & OPTICAL P.K. & THER. P.K. & TOTAL \\
\cline { 2 - 4 } & No. of Eyes $(\%)(\mathbf{n = 5 8})$ & No. of Eyes $(\boldsymbol{\%})(\mathbf{n = 2 2})$ & No. of Eyes $(\boldsymbol{\%})(\mathbf{n}=\mathbf{8 0})$ \\
\hline < 3 D & $18(31.1 \%)$ & $2(9.1 \%)$ & $20(25.0 \%)$ \\
\hline 3 D - 6 D & $12(20.7 \%)$ & $2(9.1 \%)$ & $14(17.5 \%)$ \\
\hline > 6 D & $8(13.8 \%)$ & 0 & $8(10.0 \%)$ \\
\hline Irregular Mires & $6(10.3 \%)$ & $4(18.2 \%)$ & $10(12.5 \%)$ \\
\hline $\begin{array}{l}\text { Keratometry } \\
\text { not possible }\end{array}$ & $14(24.1 \%)$ & $14(63.7 \%)$ & $28(35.0 \%)$ \\
\hline
\end{tabular}

TABLE 7 : POST OPERATIVE COMPLICATION AFTER P.K.

\begin{tabular}{|l|l|l|l|}
\hline \multirow{2}{*}{ Complication } & OPTICAL P.K. & THER. P.K. & TOTAL \\
\cline { 2 - 4 } & $\begin{array}{l}\text { No. of Eyes } \mathbf{( \% )} \\
(\mathbf{n = 5 8})\end{array}$ & $\begin{array}{l}\text { No. of Eyes } \mathbf{\%}) \\
(\mathbf{n = 1 1})\end{array}$ & $\begin{array}{l}\text { No. of Eyes } \\
(\mathbf{n = 4 0 )}\end{array}$ \\
\hline Wound Leak & 0 & $2(9.1 \%)$ & $2(2.5 \%)$ \\
\hline $\begin{array}{l}\text { Persistent Epithelial } \\
\text { Defect }\end{array}$ & $2(3.4 \%)$ & $2(9.1 \%)$ & $4(5.0 \%)$ \\
\hline $\begin{array}{l}\text { Recurrence of Fungal } \\
\text { Keratitis }\end{array}$ & 0 & $2(9.1 \%)$ & $2(2.5 \%)$ \\
\hline Suture Infiltration & $2(3.4 \%)$ & 0 & $2(2.5 \%)$ \\
\hline Graft Failure & $12(20.6 \%)$ & $14(63.7 \%)$ & $26(32.5 \%)$ \\
\hline
\end{tabular}

